\title{
E2 AND M1 TRANSITION PROBABILITIES IN IONS OF THE NITROGEN ISOELECTRONIC SEQUENCE CALCULATED USING MBPT
}

\author{
G. GAIGALAS, R. KISIELIUS, G. MERKELIS and M. VILKAS \\ Institute of Theoretical Physics and Astronomy, Gostauto 12, 2600, Vilnius, Lithuania
}

Forbidden electric quadrupole (E2) and magnetic dipole $(M I)$ transitions are of extreme importance in astrophysics. Up to now the most extensive calculations for the nitrogen isoelectronic sequence have been done using the method proposed by C.J. Zeippen [1] or in MCHF approximation [2]. To account for electron correlations both these methods use a large list of configurations. We have chosen the stationary many-body perturbation theory (MBPT) [3] for the inclusion of the electron correlations. The calculations have been perfomed in the second order in the complete model space $1 s^{2} 2 s^{2} 2 p^{3}+1 s^{2} 2 p^{5}$. Relativistic corrections have been accounted for in the Breit-Pauli approximation. In the Table we present probabilities for electric quadrupole $W(E 2)$ and magnetic dipole $W(M I)$ transitions (in $\mathrm{s}^{-1}$ ), wavelengths $\lambda$ (in A). The comparision of the results shows that our second order calculation data in the most cases are closer to term-energy corrected ones from [1].

\begin{tabular}{|lc|c|c|c|c|}
\hline \multirow{2}{*}{1} & \multicolumn{2}{|c|}{ MBPT } & \multirow{2}{*}{$\begin{array}{c}\text { MCHF } \\
{[2]}\end{array}$} & $\begin{array}{c}\text { Recommended } \\
{[1]}\end{array}$ \\
\cline { 2 - 4 } & \multicolumn{2}{|c|}{$\begin{array}{l}\text { First } \\
\text { order }\end{array}$} & $\begin{array}{l}\text { Second } \\
\text { order }\end{array}$ & & \\
\hline O II & $W(E 2)$ & $4.30-5$ & $2.11-5$ & $1.88-5$ & $2.36-5$ \\
& $W(M I)$ & $1.66-4$ & $1.20-4$ & $1.31-4$ & $1.29-4$ \\
& $\lambda$ & 3329.1 & 3821.1 & 3569.7 & $3727.1^{*}$ \\
Ne IV & $W(E 2)$ & $4.05-4$ & $2.55-4$ & $2.24-4$ & $2.46-4$ \\
& $W(M I)$ & $6.40-3$ & $4.73-3$ & $4.74-3$ & $5.52-3$ \\
& $\lambda$ & 2237.8 & 2451.5 & - & $2422.5^{*}$ \\
$\mathrm{~S} X$ & $W(E 2)$ & $2.44-2$ & $1.95-2$ & $1.77-2$ & $1.89-2$ \\
& $W(M I)$ & $1.73+1$ & $1.43+1$ & $1.40+1$ & $1.50+1$ \\
& $\lambda$ & 1160.0 & 1212.6 & 1186.7 & $1213.6^{*}$ \\
\hline
\end{tabular}

* $-\lambda \exp$ from [1]

1. S.R. Becker, K. Butler, C.J. Zeippen, 1989, Astron. Astrophys. 221, 375

2. M. Godefroid, Ch. Froese-Fischer, 1984, J. Phys. B, 17, 681.

3. M.J. Vilkas, G. Gaigalas, G. Merkelis, 1991, Lithuanian J.Phys. 31, 84 